Proceedings

\title{
Provisions for Urban Social Sustainability in City Planning: A conceptual framework
}

\author{
Azra Zainab Shabbir Ahamed 1*
}

\section{Azra Zainab Shabbir Ahamed}

1 Doctoral Candidate, School of Architecture and Planning, University of Auckland, New Zealand;
ash856@aucklanduni.ac.nz
* Correspondence: ash856@aucklanduni.ac.nz

Citation: S Ahamed, A., 2022, Provisions for Urban Social Sustainability in City Planning: a conceptual framework. SUPTM 2022 conference proceedings sciforum-054412.

https://doi.org/ 10.31428/10317/10493

Publisher's Note: UPCT and Sciforum stays neutral with regard to jurisdictional claims in published maps and institutional affiliations.

Copyright: (c) 2022 by the authors. Submitted for possible open access publication under the terms and conditions of the Creative Commons Attribution (CC BY) license (https://creativecommons.org/license s/by/4.0/).

\begin{abstract}
The success of sustainable urban planning lies with the accomplishment of environmental, economic, and social sustainability in urban areas. However, the requirements of a socially sustainable city are very unclear. This paper aims to bridge the existing theories on urban social sustainability across disciplines to provide planning pathways for socially sustainable cities. Critically reflecting on the current literature, this paper offers a detailed exploration of sustainable urban planning through the social lens. The study results in a conceptual framework by delineating three aspects: social environment, accessibility, and social infrastructure, as key contributors and discussed in detail.
\end{abstract}

Keywords: Urban Social Sustainability; Socially sustainable city; Urban Planning Framework

\section{Introduction}

The three aspects of sustainability are not integrated holistically [1] owing to a lack of a clear definition and understanding of social sustainability as the other two dimensions. Equality in the three sustainability models is an ardently discussed subject; whether or not social sustainability research should be given equal weightage to economic and environmental sustainability remains primarily unsolved. Social dimensions of sustainability, usually known as social sustainability, continue to be an essential aspect of sustainable development discourse [2]. Social sustainability is a versatile concept staying relevant in various scales of the built environment, with individual building blocks of a city constantly contributing to the impact of the social sustainability of cities. This potential could be explored and harnessed with the urban planning of cities. This study argues that further conceptual understanding of the social components of city-level sustainable development via planning is necessary. Long term, such a model will provide a robust basis for development that is both egalitarian and sustainable.

\section{Research Methods}

Using qualitative techniques, a comprehensive literature study was conducted to acquire a complete picture of the social sustainability scenario and to investigate how these themes may be addressed in future city planning prospects. Forty-three studies were discovered and analyzed using academic databases and bibliographies of published 
papers. These studies varied in terms of type, scope, discipline, scale, and sources. They were categorized into theoretical and conceptual, empirical with case studies, and relationship analysis between social sustainability indicators or urban aspects.

\section{Exploring Social Sustainability in City Planning and Design}

The area being least researched in sustainability: the social, emerges as a complex concept proving difficult to define [3]. The process of recognizing the practicality of social sustainability entails multiple dimensions of research across disciplines, including urban planning engaging the city [4], urban design involving the urban neighborhoods [5] and rural neighborhoods [6], and architectural scale referring to individual building units [7]. It also indicates that conceptualizing social sustainability at multiple scales ultimately benefits the social sustainability of cities. The literature analysis reveals commonality in the key dimensions considered for social sustainability in cities in quantitative (such as urban form, density, and physical factors of built environment), qualitative (such as personal factors and opinions), and a combination of both as discussed in Table 1.

Table 1. Contributing factors for Urban Social Sustainability of cities as identified in the literature grouped thematically; Sources: [4], [8]-[11]

\begin{tabular}{lll}
\hline \multicolumn{1}{c}{ Qualitative Indicators } & \multicolumn{1}{c}{ Quantitative Indicators } & \multicolumn{1}{c}{$\begin{array}{c}\text { Qualitative and Quantitative } \\
\text { Indicators }\end{array}$} \\
\hline Social Cohesion & Social Capital & Social inclusion \\
Equity & Access to open spaces/recreation & Community participation \\
Procedural fairness & Equal access to job opportunities & Safety \\
Fair distribution of income & Equal access in connectivity & Health risk and well-being \\
Pride of Place & Equal education access and opportunity & Environmental justice \\
social mixing/ cultural unity & Affordable housing & Social segregation \\
Safety and trust & Access to local services & Safety and security \\
Citizenship & Basic needs, facilities, and opportunities & Social interaction \\
\hline Cultural diversity & Availability of open recreational spaces & Living environment \\
\hline
\end{tabular}

The earliest social sustainability indicators were "equity, community and urbanity" [8] and extended later. While some researchers have identified the relationship of the neighborhood to its context as key indicators such as equity and choice, access to facilities, infrastructure, etc. [4], [11], [12], other researchers have focussed on the factors within societies of qualitative nature such as sense of community, social interaction, housing satisfaction etc., as indicators [2], [5], [13]. Few researchers have questioned this approach and have proposed an integrated set of indicators shortlisted from quantitative and qualitative aspects of community living [10], [14].

\section{An overarching conceptual framework for Urban Social Sustainability in City Plan- ning}

Based on the analysis, the conceptual framework proposed for including social sustainability in planning delineates three key dimensions: Social environment, accessibility, and social infrastructure.
4

5

6

7

8

9

10

11

12

13

14 


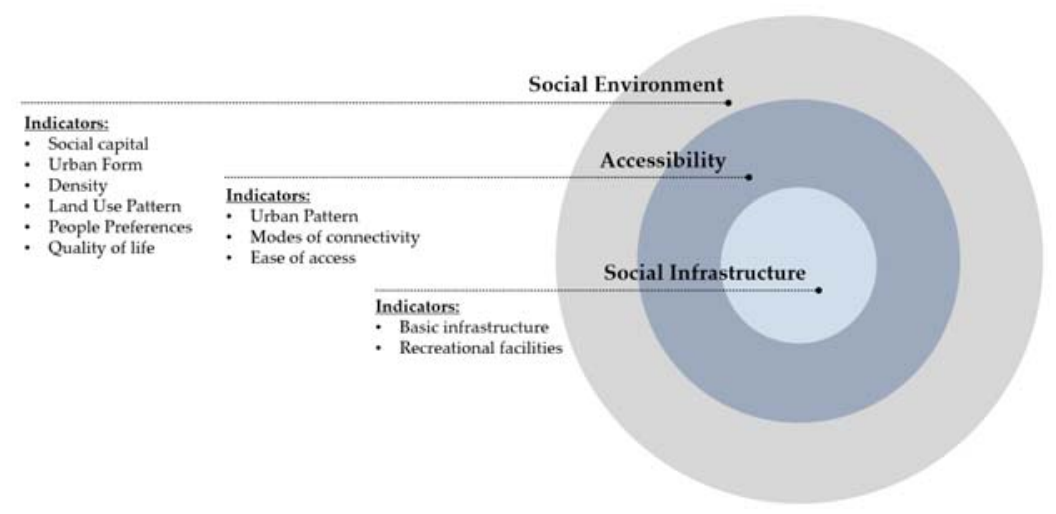

Figure 2. The overarching conceptual framework for Urban Social Sustainability in City Planning

\subsection{Social environment}

The leading social sustainability indicators focused on design parameters and individual perception [15]. In contrast, the social sustainability indicators in the built environment shifted towards responsiveness to social needs, responsiveness to cultural values, quality of life, adaptability, safety, security, participation, and accessibility (inclusive/universal design) [16]. Furthermore, fairness, sustainability awareness, involvement, and social cohesiveness are considered contributors [17]. To provide a clear unifying and quantifying measure to the social environment dimension, the study identifies six indicators: Social capital, Urban Form, Density, Land Use Pattern, People Preferences, and Quality of life.

\subsection{Accessibility}

Accessibility implies not just making it simple for community members to travel to (and from) the center, but also being universally accessible and providing direction and easy access to various facilities. Equity in access to basic services and recreational facilities determines the social success of the community. Drawing upon literature, three indicators are proposed for quantifying the accessibility dimension of urban social sustainability in cities: Urban Pattern, modes of connectivity, and ease of access.

\subsection{Social Infrastructure}

In many cities, infrastructure has been used as a catalyst to encourage the rise of community settlements. In addition to urban infrastructure, social infrastructure refers to the foundational services and networks that benefit societies, such as the education system, health care, and the administration of education and health services, which comprise the notion of basic social infrastructure. Considering the significant role of urban and social infrastructure, the study puts forth two indicators for planning practices: Basic infrastructure and Recreational facilities.

\section{Conclusion}

It is argued that social sustainability requires different operational frameworks at different scales of the urban environment. This study adds to the expanding body of research on social sustainability by giving an overview of the concept and related ideas at a city scale and identifying social sustainability dimensions for planning and associated quantifiable indicators. These underlying characteristics at the forefront of urban social sustainability discourse are social environment, accessibility, and social infrastructure. 
Funding: This research received no external funding.

Acknowledgments: The author would like to thank Dr.Farzaneh Haghighi and Dr. Paola Boarin for their supervision during the initial stage of this research.

Conflicts of Interest: The author declares no conflict of interest.

\section{References}

[1] B. Littig and E. Griessler, “Social sustainability: A catchword between political pragmatism and social theory," Int. J. Sustain. Dev., vol. 8, no. 1-2, pp. 65-79, 2005, doi: 10.1504/ijsd.2005.007375.

[2] M. R. Shirazi and R. Keivani, “Critical reflections on the theory and practice of social sustainability in the built environmenta meta-analysis," Local Environ., vol. 22, no. 12, pp. 1526-1545, 2017, doi: 10.1080/13549839.2017.1379476.

[3] V. Shrivastava and J. Singh, “Social sustainability of residential neighbourhood: A conceptual exploration," Int. J. Emerg. Technol., vol. 10, no. 2, pp. 427-434, 2019.

[4] S. M. Opp, “The forgotten pillar: a definition for the measurement of social sustainability in American cities," Local Environ., vol. 22, no. 3, pp. 286-305, 2017, doi: 10.1080/13549839.2016.1195800.

[5] N. Dempsey, G. Bramley, S. Power, and C. Brown, “The social dimension of sustainable development: Defining urban social sustainability," Sustain. Dev., vol. 19, no. 5, pp. 289-300, 2011, doi: 10.1002/sd.417.

[6] L. Wan and E. $\mathrm{Ng}$, “Evaluation of the social dimension of sustainability in the built environment in poor rural areas of China," Archit. Sci. Rev., vol. 61, no. 5, pp. 319-326, 2018, doi: 10.1080/00038628.2018.1505595.

[7] Hatipoglu, “Understanding Social Sustainability in Housing Form the Case Study 'Wohnen Mit Uns' in Vienna and Adaptibility to Turkey," Iconarp Int. J. Archit. Plan., vol. 5, no. 1, pp. 87-109, 2017, doi: 10.15320/iconarp.2017.19.

[8] O. Yiftachel and D. Hedgcock, “Urban social sustainability. The planning of an Australian city,” Cities, vol. 10, no. 2, pp. 139157, 1993, doi: 10.1016/0264-2751(93)90045-K.

[9] L. Knippenberg, T. Beckers, W. Haarmann, F. Hermans, J. Dagevos, and I. Overeem, “Developing tools for the assessment of sustainable development in the province of Brabant, the Netherlands," Sustain. Indic. Assess., no. January, pp. 309-328, 2007.

[10] S. Hemani, A. K. Das, and A. Chowdhury, "Influence of urban forms on social sustainability: A case of Guwahati, Assam," Urban Des. Int., vol. 22, no. 2, pp. 168-194, 2017, doi: 10.1057/s41289-016-0012-x.

[11] A. Rashidfarokhi, L. Yrjänä, M. Wallenius, S. Toivonen, A. Ekroos, and K. Viitanen, “Social sustainability tool for assessing land use planning processes," Eur. Plan. Stud., vol. 26, no. 6, pp. 1269-1296, 2018, doi: 10.1080/09654313.2018.1461811.

[12] G. Bramley and S. Power, "Urban form and social sustainability: The role of density and housing type," Environ. Plan. B Plan. Des., vol. 36, no. 1, pp. 30-48, 2009, doi: 10.1068/b33129.

[13] T. Larimian and A. Sadeghi, "Measuring urban social sustainability: Scale development and validation," Environ. Plan. B Urban Anal. City Sci., vol. 48, no. 4, pp. 621-637, 2019, doi: 10.1177/2399808319882950.

[14] C. Weingaertner, “Exploring Social Sustainability: Learning from Perspectives on Urban Development and Companies and Products," Sustain. Dev., pp. 1-6, 2011.

[15] S. Karuppannan and A. Sivam, "Social sustainability and neighbourhood design: An investigation of residents' satisfaction in Delhi," Local Environ., vol. 16, no. 9, pp. 849-870, 2011, doi: 10.1080/13549839.2011.607159.

[16] K. Galal Ahmed, "Evaluation of social and cultural sustainability in typical public house models in Al Ain, UAE," Int. J. Sustain. Dev. Plan., vol. 6, no. 1, pp. 49-80, 2011, doi: 10.2495/SDP-V6-N1-49-80.

[17] A. B. Eriksson, “RESIDENTIAL DESIGN IMPLEMENTING SOCIAL SUSTAINABILITY : Towards a Paradigm Shift w ithin Design Thinking ?," pp. 1-10, 2012. 